Marcel Noßmann*

\title{
Optimization of a molecular diagnostic strategy to verify SARS-CoV-2 infections by RT-qPCR
}

https://doi.org/10.1515/labmed-2020-0106

Received September 4, 2020; accepted October 11, 2020;

published online October 23, 2020

\section{Abstract}

Objectives: Fast and precise detection of SARS-CoV-2 RNA in infected patients is essential for treatment decisions.

Methods: A diagnostic strategy by analyzing nasopharyngeal swabs to detect SARS-CoV-2 RNA in individuals was established. The negative impacts of the individual buffer components on RT-qPCR analysis was reviewed and overcome by RNA purification. To investigate the functionality of the improved protocol we compared the novel diagnostic strategy to a Bead-based RNA extraction method using previously positive tested samples.

Results: A method to extract purify RNA molecules from SARS-CoV-2 was established. We examined the significance of nucleic acid purification and the need for an RNase inhibitor. Evaluation of 3,664 samples from March 23rd until May 18th in 2020 showed the incidence of COVID-19 infections in Thuringia, Germany. Additionally, benefits and limits of three RT-qPCR kits were assessed.

Conclusions: Our study suggests that virus capsid lysis combined with nucleic acid purification enables a viable alternative for the molecular diagnostics of SARS-CoV-2 infections. Due to the current delivery delays from different companies, this method offers the possibility to continue diagnosis and to handle the large number of samples.

Keywords: COVID-19; incidence in Thuringia; molecular diagnostic; RNA extraction; RT-qPCR; SARS-CoV-2.

\section{Introduction}

In December 2019, the novel coronavirus disease 19 (COVID-19) caused by severe acute respiratory syndrome coronavirus 2 (SARS-CoV-2) was affecting several million individuals in countries around the world [1]. There have been two events in the past two decades wherein crossover

\footnotetext{
*Corresponding author: Dr. Marcel Noßmann, Gemeinschaftspraxis für Laboratoriumsmedizin, Blumenstr. 70, 99092 Erfurt, Germany, E-mail: marcel.nossmann@gmx.de
}

of animal betacorona viruses to humans has resulted in severe diseases: SARS-CoV and the Middle East respiratory syndrome coronavirus (MERS-CoV) [2]. SARS-CoV-like viruses were already classified as an emerging and reemerging infection in 2007 by Cheng et al. since coronaviruses are well known to undergo genetic recombination [3]. Genomic analysis reveals a 79\% sequence identity of SARS-CoV-2 compared to SARS-CoV. SARS-CoV caused a major outbreak in 2002-2003. Based on an 88-96\% sequence similarity of phylogenetic analysis, it is currently thought that this virus originates from a bat host [4]. Occurring mutations will lead to new genotypes that may cause novel outbreaks [5]. The single-stranded RNA coronavirus is minute in size $(65-125 \mathrm{~nm}$ in diameter) and consists of a genome with up to $32 \mathrm{kbs}[6,7]$. As already shown, the SARS-CoV-2 uses the human ACE2 receptor for cell entry and the serine protease TMPRSS2 for $S$ protein priming in cell lines [8].

COVID-19 infection results in different clinical features include fever, cough, sore throat, headache, fatigue, myalgia and breathlessness. However, the clinical features are varied, ranging from asymptomatic state to acute respiratory distress syndrome and multi-organ dysfunction [9].

There is no current evidence to recommend any specific anti-SARS-CoV-2 treatment for people with a COVID-19 infection. Several clinical trials in laboratories around the world are underway to investigate the efficacy of new antiviral drugs, convalescent plasma transfusion, and vaccines. However, the results of these studies will take a long time to complete $[10,11]$. Until then, medical health care professionals are trying to take care of infected individuals. For this, fast and reliable diagnostic is essential to decide on further treatments. Molecular test for rapid detection of this virus are urgently needed for early identification of infected people. For SARS-CoV-2, the most commonly employed targets include the structural nucleocapsid $(N)$ and spike $(S)$ genes, as well as the nonstructural RNA-dependent RNA polymerase $(R d R p)$ genes [3, 12].

The reaction inhibition of RT-qPCR by different buffer compounds is a major challenge for the qualitative and quantitative detection of the molecular diagnostic or gene expression. To overcome these challenges, we aimed to establish an RNA extraction-free strategy by purifying RNA molecules via nucleic acid precipitation. 
The aim of this study was to compare three different molecular diagnostic strategies by analyzing hundreds of nasopharyngeal swabs as well as assess benefits and limits of three RT-qPCR kits.

\section{Materials and methods}

For this prospective study, dry nasopharyngeal collagen swabs were used to collect material of individuals from Erfurt, Weimar, Arnstadt and Sömmerda in Thuringia, Germany. Sample preparation and cell harvesting were performed in a class II biological safety workbench.

\section{Bead-based RNA extraction using innuPREP RNA VIRUS PLUS Kit - KFFLX (MDX) from Analytik Jena}

Nasopharyngeal swabs were incubated with $1 \mathrm{ml}$ Lysis Solution RL containing Carrier mix (Lysis/Carrier-Solution) for at least $5 \mathrm{~min}$ and mixed thoroughly by using a vortex mixer to capture the entire material. $550 \mu \mathrm{L}$ from each sample were transferred into 96 Deep Well Binding Plate (BP). Furthermore, we used $550 \mu \mathrm{L}$ Lysis/Carrier-Solution w/o human material as a negative extraction control (NEC) to verify each extraction and check for contamination. KingFisher Flex device was used for cell lysis. Subsequently, $450 \mu \mathrm{L}$ Binding Solution RBS as well as $50 \mu \mathrm{L}$ MAG Suspension were added to each well containing sample or the NEC. MAG bead suspension was mixed thoroughly using a vortex mixer or vigorous shaking before use. Respective washing solutions were transferred into the different Washing Plates. For solving the RNA $80 \mu \mathrm{L}$ RNase-free A. dest in each well of the elution plate were used. RNA extraction was performed by KingFisher Flex devise.

\section{RNA purification by Direct-Lysis and nucleic acid precipitation}

In order to make nucleic acids available for subsequent diagnostic, we established an extraction free method according to previous studies for influenza virus from Shatzkes et al. [13]. Human nasopharyngeal cells containing virus particles from dry collagen swabs were harvested in $250 \mu \mathrm{L} 1 \times$ PBS solution (Fisher Scientific; 10173433) using a class II biological safety workbench. Cell lysis was done by exposing $100 \mu \mathrm{L}$ of obtained cell solution to $100 \mu \mathrm{L}$ Direct-Lysis buffer (DL buffer) containing $10 \mathrm{mM}$ Tris pH 7.5 (VWR; A4263.0500), 0.46\% IGEPAL CA-630 (Thermo Fisher; J61055) and $150 \mathrm{mM} \mathrm{NaCl}$ (Thermo Fisher; AM9760G). Alternatively, cell solution was exposed to DL buffer with addition of 1\% (v/v) RNasin (Promega; N2615) (DLR buffer). DL/DLR buffer were freshly prepared on the day of experimentation using nuclease-free water (VWR; E476) and stored at room temperature (RT) until use. Sputum samples or bronchoalveolar lavages were homogenized and mixed directly with the lysis buffer. This suspension was incubated for $30 \mathrm{~min}$ at RT for cell disruption and virus capsid lysis. With addition of RNase inhibitor, the incubation time could be expanded up to several hours to increase the efficiency of lysis reaction. To overcome the negative impact of buffer components the nucleic acids were subsequently purified by adding $1 / 10$ volume of $3 \mathrm{M}$ sodium acetate pH 5.2 (VWR, E498) and 3 volume $96 \%$ (v/v) ethanol (freeze at $-20^{\circ} \mathrm{C}$ prior use). Samples were incubated for up to $60 \mathrm{~min}$ at
$4{ }^{\circ} \mathrm{C}$ to precipitate nucleic acids. This precipitation step can be extended to increase the yield of RNA/DNA. The authors recommend to perform this incubation step not less than $30 \mathrm{~min}$. Subsequently, samples were centrifuged at $13.000 \mathrm{~g}$ for $10 \mathrm{~min}$ to pellet the nucleic acids. RNA/DNA pellet was washed two times by adding $1 \mathrm{~mL}$ of cooled $70 \%(\mathrm{v} / \mathrm{v})$ ethanol and mixed using a vortex shaker. Finally, the pellet was washed one time using $1 \mathrm{~mL}$ of cooled $96 \%$ (v/v) ethanol. After drying, the resulting sediments were carefully collected, rigorous dissolved in $20 \mu \mathrm{L}$ of nuclease-free water and either analyzed immediately or short-term stored at $4{ }^{\circ} \mathrm{C}$ (long-term storage at $-20{ }^{\circ} \mathrm{C}$ ). Statistical analysis was done by normal distribution ' $z$ ' test.

\section{RT-qPCR analysis}

Experiments were carried out according to the respective manufacturer's instructions. Investigation of effects of buffer components on RT-qPCR were performed using MutaPLEX ${ }^{\circledR}$ Coronavirus RT-PCR kit [KG192696] from Immundiagnostik company. Verification of DL combined with nucleic acid precipitation method were performed using GeneFinder COVID-19 Plus RealAmp kit [IFMR-45] from HISS Diagnostics company. Comparison of RT-qPCR analysis was carried out with kits previously mentioned and with Coronavirus COVID-19 genesig® ${ }^{\circledR}$ Real-Time PCR assay kit [Z-PATH-COVID-19-CE] from Hain Life Science company. Reverse transcription and subsequent amplification of generated cDNA molecules was done in a One-Step-Reaction in all kits used in this study. Each sample containing master mix and purified RNA molecules was analyzed with ABI 7500 PCR cycler in a 96 well plate from Abbott Molecular company. In all experiments only the $\mathrm{Ct}$ value and the fluorescence intensity were assessed, there was no quantitative analysis using a standard curve and no melting curve analysis. This could not be done with the cycler used.

\section{Results}

\section{Incidence of COVID-19 infections in Thuringia}

Within eight weeks 3,627 collagen swabs and 37 bronchoalveolar lavages (BAL) were analyzed via RT-qPCR resulting in 121 individuals infected with SARS-CoV-2. Human materials were obtained from Erfurt, Weimar, Arnstadt and Sömmerda (Thuringia, Germany). The extension of testing criteria by Robert-Koch-Institute (RKI) enables a more precise determination of the rate of new infections in this area from March 23rd until May 18th in 2020. A linear increase of infections was found in the period shown in Figure 1.

\section{Influences of individual buffer components for RT-qPCR}

We reviewed possible negative effects of the individual buffer components on the RT-qPCR analysis. For sample 


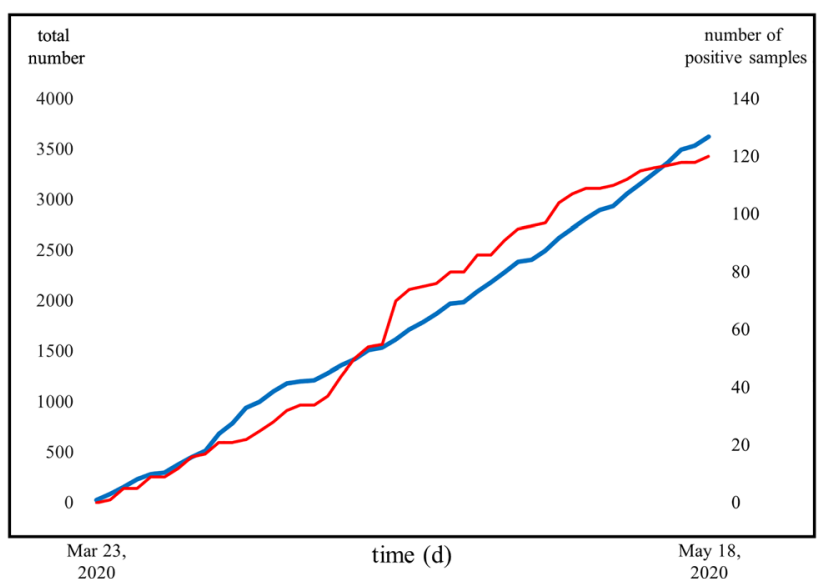

Figure 1: Incidence of COVID-19 infections in Thuringia. The x-axis shows the period from Mar 23, 2020 until May 18, 2020. Total number of samples shown in blue are related to positive numbers shown in red.

preparation, patient material on dry collagen swabs were harvested in $10 \mathrm{mM}$ PBS buffer and mixed with the appropriate volume DL or DLR lysis buffer. To evaluate the influence of the individual reagents included in these buffers as well as their combinations on RT-qPCR assay, Ct values and fluorescent signal power were measured using the Immundiagnostik kit. We decided to use the RT-qPCR kits from HISS Diagnostics and Immundiagnostik for the experiments since both kits determine three independent genes from SARS-CoV2 leading to a reliable investigation of putative infected samples. The Ct values of both kits were compared using RNA of three previous positive tested patients. Since the determined Ct values for the RdRp gene and the $\mathrm{E}$ gene resulted in a similar range (date not shown) we decided to use both kits for further experiments. We first investigated the inhibitory effects of $10 \mathrm{mM}$ PBS buffer, DL buffer w/o RNasin, DL buffer $\mathrm{w} / \mathrm{RNasin}(0.5$ and $1 \%$ ), respectively, by adding $6 \mu \mathrm{L}$ of those compounds to the RT-qPCR reaction. The addition of PBS leads to an increase of $2 \mathrm{Ct}$ values, whereas DL buffer w/o RNasin increased the $\mathrm{Ct}$ values by 3.5, compared to the negative and water control (Figure 2).

These results are accompanied by a simultaneous loss of the fluorescent signal power up to $50 \%$ for the sample containing PBS and up to 70\% for the DL buffer w/o RNasin (Figure 3). Surprisingly, the increase of $\mathrm{Ct}$ values were lower (2.5 and 2) when 0.5 and $1 \%$ RNasin were added to DL buffer, respectively (Figure 2). The signal power showed no significant difference compared to samples w/o RNasin. We further investigated the inhibitory effect of DL buffer with addition of PBS resulting in an accumulation of the inhibitory effects. A 1:2 dilution showed a delay of more than 1 cycle of the $\mathrm{Ct}$ values compared to the controls, the

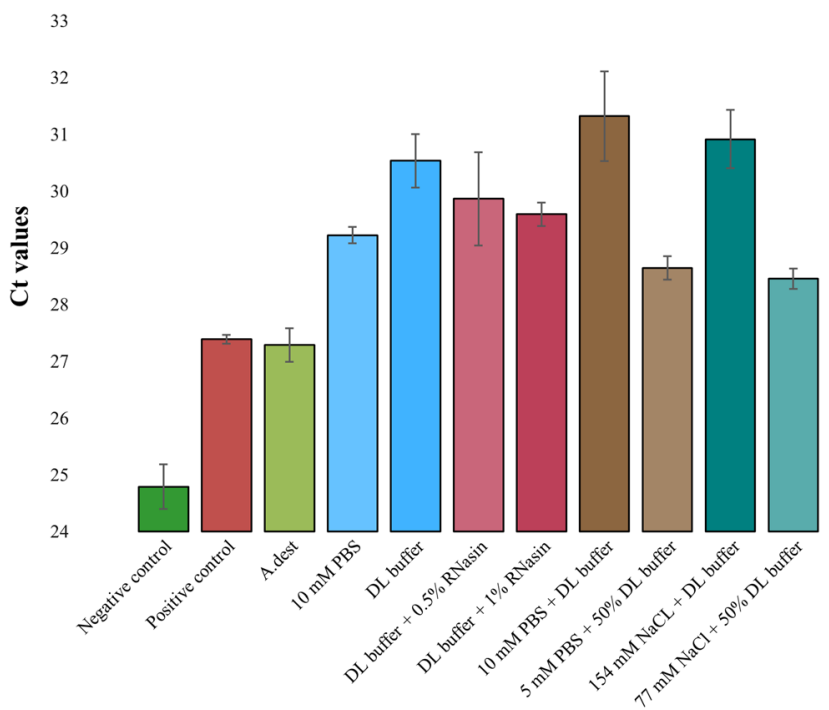

Figure 2: Inhibitory effect on the Ct values of the internal control. $\mathrm{Ct}$ values (y-axis) are shown when an amplificate of the internal control appears for the first-time using RT-qPCR kit from Immundiagnostik company. $\mathrm{n}=3$; purified RNA was used as an internal control in all samples independently from additional added reagents. DL, Direct Lysis buffer.

fluorescent signal power was four times higher compared to the undiluted sample. Harvesting cells and viral RNA in PBS buffer is not absolutely necessary. Thus, we further tested the inhibitory effects of $154 \mathrm{mM} \mathrm{NaCl}$ solution. These results in Figures 2 and 3 further demonstrated no evident effect of using $\mathrm{NaCl}$ instead of PBS.

\section{Comparison of Bead-based RNA extraction and Direct-Lysis combined with nucleic acid precipitation}

People previously tested positive for SARS-CoV-2 infection were confirmed positive when testing with DLR method. For this, dry nasopharyngeal swab samples were freshly collected after patient's approval. The harvested material of the respective collagen swabs was portioned equally for Bead-based extraction, DL w/o RNasin and DL w/ RNasin, respectively, or freshly collected from BAL of the same patient to compare the results.

To investigate the functionality of the improved diagnostic protocol we compared the DL and the DLR (containing 1\% RNasin) method of three previously positive tested patients (Table 1, sample 1-3) and one negative control (Table 1, sample 4) versus the Bead-based RNA extraction method. For this, the presence of the $R d R p$ (RNA dependent RNA polymerase) gene, the $E$ (envelope) gene, the 


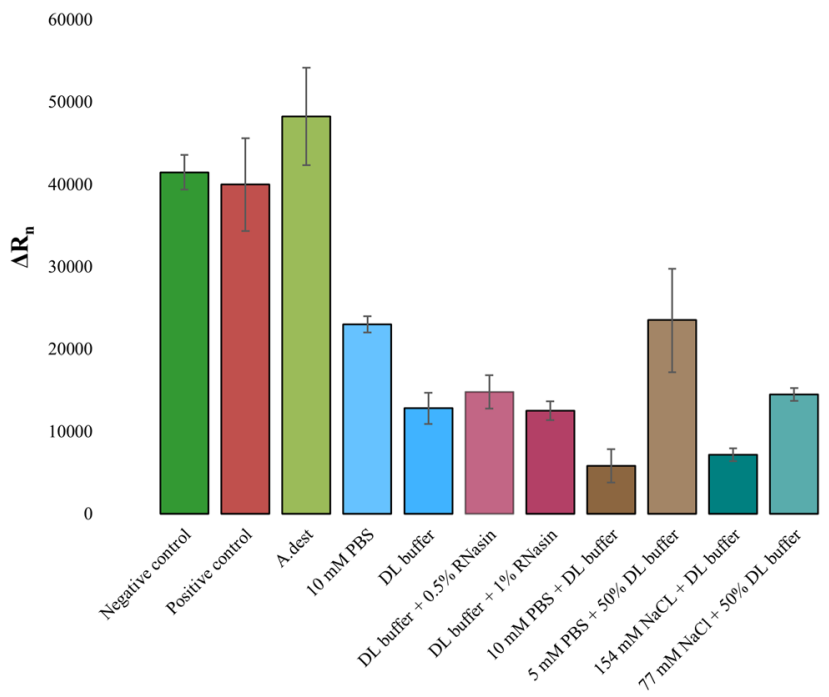

Figure 3: Inhibitory effect on the signal power of the internal control.

Signal power (y-axis, $\Delta R n$ ) are determined manually at cycle 35 of each sample using RT-qPCR kit from Immundiagnostik company. $n=3$; purified RNA was used as an internal control in all samples independently from additional added reagents; DL, Direct Lysis buffer.

$N$ (nucleocapsid) gene and a control RNA were determined by RT-qPCR. The human sample material was divided into three equal parts and immediately analyzed. To compare these methods, we first determined the volume to get the cells into solution. Unfortunately, dry swabs are not produced evenly resulting in differences regarding stick length and swab size. We tested $100 \mu \mathrm{L}, 150 \mu \mathrm{L}, 200 \mu \mathrm{L}, 250 \mu \mathrm{L}, 400 \mu \mathrm{L}, 500 \mu \mathrm{L}$ and $1 \mathrm{~mL}$ of $1 \times$ PBS/Lysis Solution RL, respectively, for harvesting patient material (data not shown). The residual volume was transferred into a $1.5 \mathrm{ml}$ tube and estimated by pipetting. On average, the remaining volume was $100-150 \mu \mathrm{L}$ less than the volume added. For the following experiment $400 \mu \mathrm{L}$ were used and divided into equal parts.

Purification of SARS-CoV-2 RNA by nucleic acid precipitation was feasible. Samples 2 and 3 showed similar results for the Bead-based and the DLR method. Analyzes of sample 1 results in a slightly positive signal only for the $N$ gene (DLR) compared to the RNA extraction sample. Furthermore, the lack of the RNase inhibitor leads to a degradation of the RNA in all samples. The DL method is not suitable for analyzing nasopharyngeal swabs from humans. As expected, there was no signal detectable in the negative control. Performing RT-qPCR assay by using nonpurified RNA molecules resulted in a total inhibition in several cases. The amplification of the target RNA as well as the housekeeping gene were completely inhibited, making the respective tests no longer evaluable.

\section{Comparison of three different kits for RT-qPCR}

To validate the performance of each RT-qPCR kit, we analyzed extracted RNA from 3,664 nasopharyngeal swabs or BAL in the routine diagnostic (Hain Life Science: 634 reactions; HISS Diagnostics: 832 reactions; Immundiagnostik: 2,530 reactions; 332 of these 3,996 reactions are analytical duplicates). Further, a positive control of each kit was added to the Lysis buffer provided in the Analytik Jena kit and the full isolation procedure was performed. Inserted control RNA could be detected with all kits (data not shown). As shown in Table 2, each kit is amplifying the $R d R p$ gene as the primary target to confirm a SARS-CoV-2 infection and an internal control to verify the assay itself.

The kits from HISS Diagnostics and Immundiagnostik also determine the $E$ and $N$ (or Spike glycoprotein $[S]$ ) genes of the coronavirus (Table 2). In addition, both kits enable the opportunity to detect a human housekeeping gene to validate sampling. Further advantages and disadvantages as well as the required fluorescence channels are listed in Table 2.

\section{Discussion}

\section{Rapid progression of new infections}

Despite the restrictions on outdoor activities, social distancing and the shutdown of many economic and commercial fields, we detected several new infections by analyzing dry nasopharyngeal collagen swabs from different sampling points in the middle of Thuringia.

Table 1: Functional verification of Direct-Lysis with nucleic acid precipitation.

\begin{tabular}{|c|c|c|c|c|c|c|c|c|c|}
\hline \multirow[b]{2}{*}{ Target } & \multicolumn{3}{|c|}{ Bead-based RNA extraction } & \multicolumn{3}{|c|}{ Direct-Lysis w/o RNasin (DL) } & \multicolumn{3}{|c|}{ Direct-Lysis w/ RNasin (DLR) } \\
\hline & $R d R p$ gene & $E$ gene & $N$ gene & $R d R p$ gene & $E$ gene & $N$ gene & $R d R p$ gene & $E$ gene & $N$ gene \\
\hline Sample 1 & wp & wp & wp & $\mathrm{n}$ & $\mathrm{n}$ & $\mathrm{n}$ & $\mathrm{n}$ & $\mathrm{n}$ & wp \\
\hline Sample 2 & $\mathrm{p}$ & $\mathrm{p}$ & $\mathrm{p}$ & $\mathrm{n}$ & $\mathrm{n}$ & $\mathrm{p}$ & $\mathrm{p}$ & $\mathrm{p}$ & $\mathrm{p}$ \\
\hline Sample 3 & $\mathrm{p}$ & $\mathrm{p}$ & $\mathrm{p}$ & $\mathrm{n}$ & $\mathrm{n}$ & wp & $\mathrm{p}$ & $\mathrm{p}$ & $\mathrm{p}$ \\
\hline Sample 4 & $\mathrm{n}$ & $\mathrm{n}$ & $\mathrm{n}$ & $\mathrm{n}$ & $\mathrm{n}$ & $\mathrm{n}$ & $\mathrm{n}$ & $\mathrm{n}$ & $\mathrm{n}$ \\
\hline
\end{tabular}

$R d R p$, RNA dependent RNA polymerase; $E$, envelope; $N$, nucleocapsid; wp, weakly positive; $\mathrm{p}$, positive; $\mathrm{n}$, negative. 
Table 2: Comparison of three tested RT-qPCR kits.

\begin{tabular}{|c|c|c|c|c|c|c|c|c|c|c|}
\hline \multirow{2}{*}{ Company } & \multicolumn{4}{|c|}{ HISS diagnostics } & \multicolumn{4}{|c|}{ Immundiagnostik } & \multicolumn{2}{|c|}{ Hain Life Science } \\
\hline & \multicolumn{4}{|c|}{$\begin{array}{l}\text { GeneFinder COVID-19 Plus RealAmp } \\
\text { kit (IFMR-45) }\end{array}$} & \multicolumn{4}{|c|}{ MutaPLEX® coronavirus RT-PCR (KG192696) } & \multicolumn{2}{|c|}{$\begin{array}{l}\text { COVID-19 genesig }{ }^{\circledR} \\
\text { real-time PCR assay } \\
\text { (Z-PATH-COVID-19-CE) }\end{array}$} \\
\hline Genes & $\begin{array}{l}R d R p \\
\text { gene }\end{array}$ & $\begin{array}{l}E \\
\text { gene }\end{array}$ & $\begin{array}{l}N \\
\text { gene }\end{array}$ & $\begin{array}{l}R \text { NaseP } \\
\text { gene }\end{array}$ & $\begin{array}{l}R d R p / S \\
\text { gene }^{\text {b }}\end{array}$ & $\begin{array}{l}\beta \text {-actin } \\
\text { gene }\end{array}$ & Egene & $\begin{array}{l}\text { Internal } \\
\text { control }\end{array}$ & $\begin{array}{l}R d R p \\
\text { gene }\end{array}$ & $\begin{array}{l}\text { Internal } \\
\text { control }\end{array}$ \\
\hline $\begin{array}{l}\text { Channel }^{\mathrm{a}} / \\
\text { Fluorophore }\end{array}$ & \multicolumn{10}{|c|}{ red } \\
\hline Benefit & \multicolumn{4}{|c|}{$\begin{array}{l}\text { Human } R N a s e P \text { as a housekeeping } \\
\text { gene. Good instruction for result } \\
\text { interpretation in the manual. }\end{array}$} & \multicolumn{4}{|c|}{ Human $\beta$-actin as a housekeeping gene. } & \multicolumn{2}{|c|}{$\begin{array}{l}\text { Analytical sensitivity was } \\
\text { tested with different } \\
\text { RT-qPCR machines. }\end{array}$} \\
\hline Limits & \multicolumn{4}{|c|}{$\begin{array}{l}\text { The negative control is missing the } \\
\text { human housekeeping gene. }\end{array}$} & \multicolumn{4}{|c|}{ Amplification of the $N$ gene is not included } & \multicolumn{2}{|c|}{$\begin{array}{l}\text { Amplification of only one } \\
\text { gene. No human house- } \\
\text { keeping gene. }\end{array}$} \\
\hline
\end{tabular}

${ }^{\mathrm{a}}$ Listed channels for Applied Biosystem ${ }^{\circledR} 7500$ RT-PCR cycler. ${ }^{\mathrm{b}}$ During this study, the Immundiagnostik company switched the amplification in the FAM channel from only the $R d R p$ gene to the $R d R p+S$ genes. $R d R p$, RNA dependent RNA polymerase; $E$, envelope; $N$, nucleocapsid; $S$, spike glycoprotein.

Regarding to the linear increase of positive tested individuals compared to an almost constant number of tests per day we found 121 new infections within just two months. This could be due to the high reproduction number of around 3, which is considerably higher than the World Health Organization (WHO) estimate at 1.95 [14].

Until now, infected patients have been isolated at home. Unfortunately, there is no current evidence to recommend any specific anti-SARS-CoV-2 treatment for infected patients. Clinical trials are underway to investigate the efficacy of new antiviral drugs, protease inhibitors, and vaccines. However, the results of these studies will take a long time to complete $[8,11]$.

\section{Bead-based RNA extraction compared to Direct-Lysis with nucleic acid precipitation}

In recent studies, many RNA extraction methods have been tested in order to analyze nasopharyngeal swabs of people. The trial by Merindol et al. showed that swabs stored in some media are not appropriate samples for direct RT-qPCR analysis [15]. Recommendations of the Charite Institute of Virology (Berlin, Germany) or confirmations of the Centers for Disease Control and Prevention (CDC) offer a range of kits for SARS-CoV-2 [16, 17].

In this study, a Bead-based RNA extraction kit and an improved manual RNA extraction method were tested to detect a COVID-19 infection.

The need for cumbersome RNA purification is circumvented when using the Direct-Lysis method to generate cell lysate accessible to direct analysis in RT-qPCR [13]. We compared the functionality of a Bead-based RNA extraction using innuPREP RNA VIRUS PLUS Kit - KFFLX (MDX) from Analytik Jena and a less expensive and manufacturer independent Direct-Lysis protocol for viruses including nucleic acid precipitation and purification (Figure 4).

Despite the efforts of all manufacturers, the availability of kits or reagents and the high costs still reveal considerable challenges to keep the diagnostic going. Furthermore, the required components of commercial reagents are undisclosed and often limited, which can stall the diagnostic when even one component or plastic materials are left. The additional purification step of the nucleic acids enables a simple opportunity to use a higher amount of the detergent IGEPAL CA-630 to lyse the virus capsid. In this study, we showed the possibility to use a concentration of $0.46 \%$ IGEPAL as recommended by Dr. Schubert et al. (Universitätsklinikum Ulm, personal message to different medical laboratories) and by Dr. Krumbholz and Dr. Lorentz (Labor Krause und Kollegen MVZ $\mathrm{GmbH}$, personal message) compared to $0.20 \%$ IGEPAL as published by Shatzkes et al. in [13].

To demonstrate the scope of the extraction free method for the SARS-CoV-2 diagnostic, we investigated the inhibitory effects of PBS buffer, DL buffer w/o RNasin, DL buffer $\mathrm{w} / \mathrm{RNasin}$ as well as the combination of PBS or $\mathrm{NaCl}$ with DL buffer and a 1:2 dilution of those combinations, respectively. As an advantage of using DLR buffer instead of DL buffer for the lysing step, it was possible to increase the incubation time of the lysis step because the inhibitor impeded the degradation of the viral RNA. The ribonuclease inhibitor RNasin was extensively tested for compatibility with different polymerases $[18,19]$. Our 


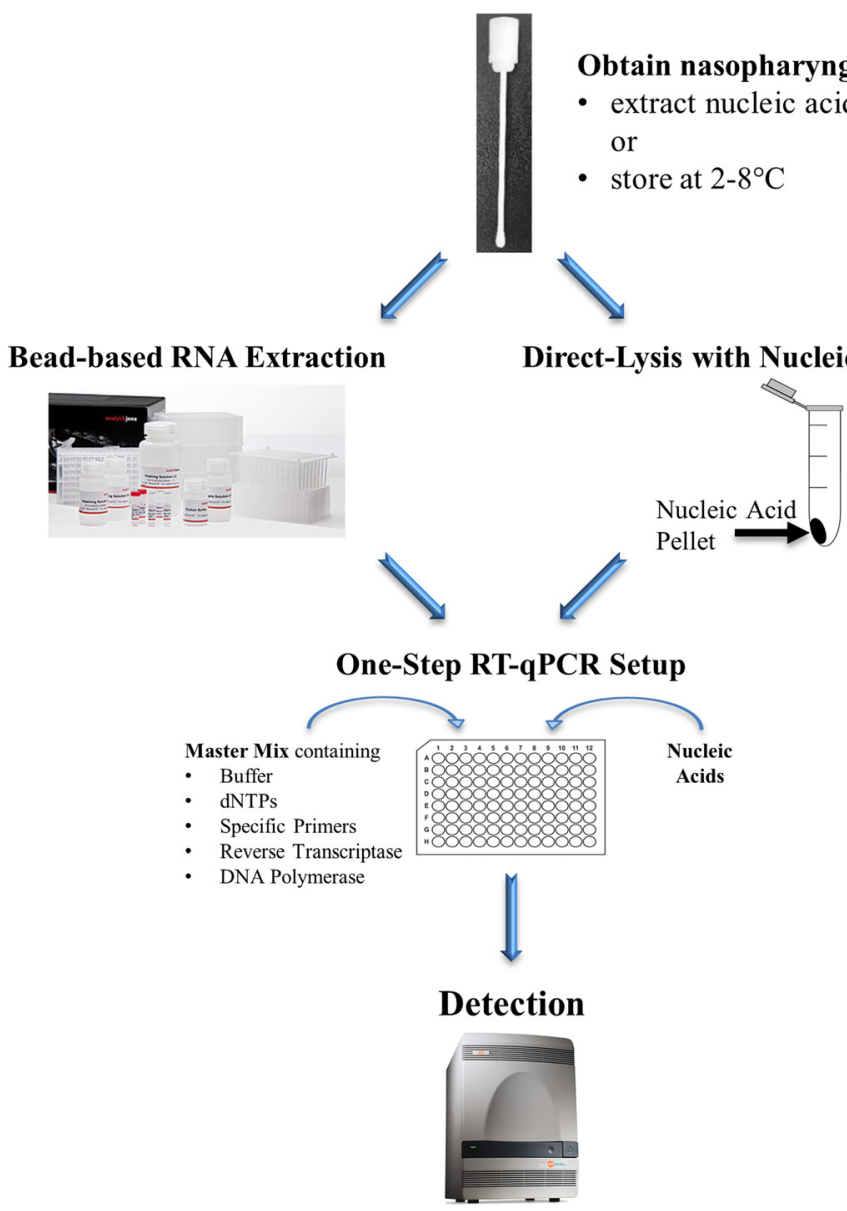

experiments confirmed those previous studies and further reveal a slight positive impact when using DLR buffer containing $0.5 \%$ or $1 \%$ RNasin on the Ct values of the internal control (Figure 2). The fluorescence signal reached the threshold one cycle earlier, using DLR buffer containing $1 \%$ RNasin, compared to the DL buffer w/o RNasin. Furthermore, the power of the fluorescent signal was slightly higher using $0.5 \%$ RNasin but similar with addition of $1 \%$ RNasin compared to the DL buffer. These differences could be explained by the small number of tested replicates leading to a large standard deviation for $0.5 \%$ RNasin (Figure 3). In this experiment, the negative control showed a lower $\mathrm{Ct}$ value than the control with $\mathrm{A}$. dest. These low $\mathrm{Ct}$ values were no longer achieved in further tests and were also in the same range as those of the positive and water controls. In order to maintain the comparability of all components, the determined values were used for evaluation. These results further reveal negative influences on the RT-qPCR caused by other reagents added to DirectLysis buffer. We showed that addition of $1 \times$ PBS leads to an increase of the Ct values by 2.5 (Figure 2) and a decrease of the fluorescent signal of more than $40 \%$. This negative
Figure 4: Scheme of strategies for RNA isolation.

Modified pictures of innuPREP RNA VIRUS PLUS Kit from Analytik Jena and Abbott m2000rt cycler were obtained from respective websites. effect of different PBS concentrations was previously studied by Zhu et al. [20]. By increasing the PBS concentration up to five times, they found gradually decrease in the PCR efficiency up to 50\%. The use of lower PBS concentrations is not recommended due to the risk of the spontaneous cell lysis due to osmotic imbalance [20]. In this study, a comparable effect could be observed after the added PBS/DL buffer was diluted 50\% with nuclease-free water. Furthermore, we showed that an exchange of $1 \times \mathrm{PBS}$ to $0.9 \% \mathrm{NaCl}$ did not improve Ct values. On the contrary, the power of the fluorescent signal even decreased. As expected, the combination of $1 \times$ PBS and DL buffer leads to an accumulation of the inhibitory effects (Figures 2 and 3). The subsequent purification step of nucleic acids circumvents these inhibitory effects since the RNA/DNA pellet was dissolved in nuclease-free water. Even if the pellet is very small and maybe invisible there are still enough RNA molecules to detect the respective housekeeping gene as well as the incidence of SARS-CoV-2 via RT-qPCR. Precipitation could be further enhanced using cooled propan-2-ol instead of ethanol or performing phenol-chloroform RNA extraction [21]. 
Without this purification step, a high rate of premature terminations or total inhibitions of those assays was not feasible for constant diagnostic investigations in medical laboratories. Current studies are concerned with detection of COVID-19 positive patient in the absence of an RNA extraction step resulting in a 18 -fold drop in sensitivity [22]. This leads to false negative results if the amount of patient's material available on the nasopharyngeal swabs is low. The higher the error rate in these tests the higher the costs for the respective laboratory as well as for the treating doctor or the hospital will be. Delaying the test results due to inhibitions leads to a prolongation of the isolation of individual patients in cases of COVID-19 infections.

In this study, we showed that the purification of SARS-CoV-2 RNA by nucleic acid precipitation is feasible. Samples from patients B and C (Table 1) clearly confirmed that this optimized method enables a viable alternative for the molecular diagnostics. In sample A, a positive signal could only be detected in one out of three genes. When the patient is already on the mend, the viral load decreases resulting in a challenge to isolate the RNA. In addition, it could be shown that the lack of the inhibitor leads to a degradation of the RNA. This effect is enhanced when analyzing several samples due to the extended time.

Furthermore, we assess benefits and limits of the three RT-qPCR kits. Comparison of these kits revealed two preferred kits for SARS-CoV-2 diagnostic. The kits from HISS Diagnostics and Immundiagnostik determine the $R d R p, E$ and $N$ (or $S$ ) genes of the coronavirus 2 (Table 2). In addition, both kits enable the opportunity to detect a human housekeeping gene to validate sampling. This allows false negative results to be determined due to incorrect sampling. All tested kits are effective for detection of viral RNA, but the use of housekeeping genes and multiple targets improves diagnostics. Mentionable, the kit from HISS Diagnostics detects the three recommended genes for SARS-CoV-2 diagnostic.

\section{Conclusions}

Our study suggests that Direct-Lysis combined with nucleic acid purification enables an efficient and economically alternative for detection of SARS-CoV-2 infections in human. Due to the current delivery delays of RNA extractions kits and the availability of pipetting devices from different companies, this method offers the possibility to continue the diagnosis and to handle the large number of samples.

Finally, we identified a linear increase of infected patients from Mar 23rd, 2020 until May 18th, 2020. Consequently, the virus was still able to spread well during the lockdown period in spring in Erfurt and the surrounding areas.

Acknowledgments: This study was supported by the Gemeinschaftspraxis Dres. med S. Sel/H. Späte and Dres. med E. Wietschel/F. Wietschel, Erfurt (Germany). Dr. Sel is acknowledged for continuous support and organization. Thank you to all doctors, nurses, and medical workers for the great job. Dr. Schubert and colleagues (Universitätsklinikum Ulm) and, Dr. Krumbholz and Dr. Lorentz (Labor Krause und Kollegen MVZ GmbH) are acknowledged for information and discussions. Dr. med. Daumann and Dr. med. Pleßmann for their work at different sampling points. Dr. med. Kirsch and their patients are acknowledged for providing sample materials. Michael Jordan, M.Sc. is acknowledged for scientific assistance. Rebecca Graul and Marleen Brieger are acknowledged for excellent technical assistance.

Research funding: None declared.

Author contributions: The author has accepted responsibility for the entire content of this manuscript and approved its submission.

Competing interests: The author states no conflict of interest.

Ethical approval: Not applicable.

\section{References}

1. Lai CC, Shih TP, Ko WC, Tang HJ, Hsueh PR. Severe acute respiratory syndrome coronavirus 2 (SARS-CoV-2) and coronavirus disease2019 (COVID-19): the epidemic and the challenges. Int J Antimicrob Agents 2020;55:105924.

2. Singhal T. A review of coronavirus disease-2019 (COVID-19). Indian J Pediatr 2020;87:281-6.

3. Cheng VC, Lau SK, Woo PC, Yuen KY. Severe acute respiratory syndrome coronavirus as an agent of emerging and reemerging infection. Clin Microbiol Rev 2007;20:660-94.

4. Lake MA. What we know so far: COVID-19 current clinical knowledge and research. Clin Med (Lond) 2020;20:124-7.

5. Woo PC, Lau SK, Yip CC, Huang Y, Tsoi HW, Chan KH, et al. Comparative analysis of 22 coronavirus HKU1 genomes reveals a novel genotype and evidence of natural recombination in coronavirus HKU1. J Virol 2006;80:7136-45.

6. Zhou P, Yang XL, Wang XG, Hu B, Zhang L, Zhang W, et al. A pneumonia outbreak associated with a new coronavirus of probable bat origin. Nature 2020;579:270-3.

7. Shereen MA, Khan S, Kazmi A, Bashir N, Siddique R. COVID-19 infection: origin, transmission, and characteristics of human coronaviruses. J Adv Res 2020;24:91-8.

8. Hoffmann M, Kleine-Weber H, Schroeder S, Kruger N, Herrler T, Erichsen S, et al. SARS-sCoV-2 cell entry depends on ACE2 and TMPRSS2 and is blocked by a clinically proven protease inhibitor. Cell 2020;181:271-80 e8. 
9. Chen N, Zhou M, Dong X, Qu J, Gong F, Han Y, et al. Epidemiological and clinical characteristics of 99 cases of 2019 novel coronavirus pneumonia in Wuhan, China: a descriptive study. Lancet 2020;395:507-13.

10. Helmy YA, Fawzy M, Elaswad A, Sobieh A, Kenney SP, Shehata AA. The COVID-19 pandemic: a comprehensive review of taxonomy, genetics, epidemiology, diagnosis, treatment, and control. J Clin Med 2020;9:1225.

11. Zhai P, Ding Y, Wu X, Long J, Zhong Y, Li Y. The epidemiology, diagnosis and treatment of COVID-19. Int J Antimicrob Agents 2020;55:105955.

12. Chu DKW, Pan Y, Cheng SMS, Hui KPY, Krishnan P, Liu Y, et al. Molecular diagnosis of a novel coronavirus (2019-nCoV) causing an outbreak of pneumonia. Clin Chem 2020;66:549-55.

13. Shatzkes K, Teferedegne B, Murata H. A simple, inexpensive method for preparing cell lysates suitable for downstream reverse transcription quantitative PCR. Sci Rep 2014;4:4659.

14. Liu Y, Gayle AA, Wilder-Smith A, Rocklöv J. The reproductive number of COVID-19 is higher compared to SARS coronavirus. J Trav Med 2020;27. https://doi.org/10.1093/ $\mathrm{jtm} / \mathrm{taaa021}$

15. Merindol N, Pépin G, Marchand C, Rheault M, Peterson C, Poirier A, et al. SARS-CoV-2 detection by direct rRT-PCR without RNA extraction. I Clin Virol 2020;128:104423.

16. Corman VM, Landt O, Kaiser M, Molenkamp R, Meijer A, Chu DK, et al. Detection of 2019 novel coronavirus (2019-nCoV) by realtime RT-PCR. Euro Surveill 2020;25:2000045.
17. Centers for Disease Control and Prevention, Division of Viral Diseases. CDC 2019-novel coronavirus (2019-nCoV) real-time RT-PCR diagnostic panel. CDC-006-00019; 2020. Available from: https://www.fda.gov/media/134922/download [Accessed 03 June 2020].

18. Andrews C, Huang F, Shultz J. RNasin $®$ Plus RNase Inhibitor: New Protein for High Temperature RNase Inhibition. Promega Corporation Website; 2003. Available from: https://www.promega.de/ resources/pubhub/enotes/rnasin-plus-rnase-inhibitor-new-proteinfor-high-temperature-rnase-inhibition/ [Accessed 14 May 2020].

19. Hopper K. RNasin ${ }^{\circledR}$ Ribonuclease Inhibitors: superior Performance for All of Your RNA Analysis Needs. Promega Corporation Website; 2004. Available from: https://www. promega.de/Resources/PubHub/Promega\%20Notes\%202004/ RNasin\%20Ribonuclease\%20Inhibitors\%20Superior\% 20Performance\%20for\%20All\%20of\%20Your\%20RNA\% 20Analysis\%20Needs/ [Accessed 14 May 2020].

20. Zhu Y, Zhang YX, Liu WW, Ma Y, Fang Q, Yao B. Printing 2-dimensional droplet array for single-cell reverse transcription quantitative PCR assay with a microfluidic robot. Sci Rep 2015;5:9551.

21. Toni LS, Garcia AM, Jeffrey DA, Jiang X, Stauffer BL, Miyamoto SD, et al. Optimization of phenol-chloroform RNA extraction. MethodsX 2018;5:599-608.

22. Bruce EA, Huang ML, Perchetti GA, Tighe $S$, Laaguiby $P$, Hoffman JJ, et al. Direct RT-qPCR detection of SARS-CoV-2 RNA from patient nasopharyngeal swabs without an RNA extraction step. PLoS Biol 2020;18:e3000896. 